\title{
Study on selecting of prefabricated plant site basing on BP neural network
}

\author{
Yao Gang ${ }^{1,2}$, Yang Yang ${ }^{1,2, a}$, Shen Xin ${ }^{1,2}$ and Li Jun ${ }^{1,2}$ \\ ${ }^{1}$ Key Laboratory of New Technology for Construction of Cities in Mountain Area, Ministry of Education, 400040, Chongqing, China \\ ${ }^{2}$ School of Civil Engineering, Chongqing University, 400040, Chongqing, China
}

\begin{abstract}
In this paper, the evaluation and prediction model of prefabricated plant site was established by BP neural network, which taking nine factors into consideration, such as location, topography, land scale, transportation facilities, availability of raw materials and labour. These nine factors were taken as input factors, and the normalized global value was taken as output factor. The normalized global value was used to evaluate the performance of prefabricated plant site. In addition, the model was verified to be accurate by analysing twelve prefabricated plant site samples. Therefore, it is obvious that the model is stable in operation with high precision, and can provide effective support in the selection of prefabricated plant site.
\end{abstract}

\section{Introduction}

With the development of architectural industrialization, the proportion of prefabricated buildings is increasing in new construction. Prefabricated building has attracted worldwide concern because of its significant role in the creation of sustainable urbanization.

But the practice of applying prefabrication technology in the construction industry still lags behind comparing with the developed Western countries. It is estimated that the proportion of prefabricated construction in China will account for more than $15 \%$ of new construction in the 2020 year, of which the key promoted areas are more than $20 \%$, the actively promoted areas are more than $15 \%$, and areas that are encouraged to promote are more than $10 \%$. In addition, over fifty demonstration cities of prefabricated architecture, more than two hundred prefabricated building industrial bases and above five hundred demonstration projects of prefabricated buildings will be cultivated in the 2020 year. Furthermore, beyond thirty prefabricated building technology innovation bases will be built. But the practice of applying prefabrication technology in the construction industry still lags behind. Therefore, the market for prefabricated components will be in short supply. A large number of prefabricated plant will emerge in various places, and the location of new prefabricated plant will become a hot issue.

A number of scholars have done some research on the prefabricated construction and prefabricated plant. S.H. Jiang [1] took the TOMID theory in selecting prefabricated construction factory. A series of decision criteria were set up for the location selection of prefabricated industries. On the basis of the decision criteria, TOMID method was applied to evaluate and sort various schemes, and its sensitivity was analysed. J.D.
Qin [2] presented an extended TODIM multi-criteria group decision to make method for green supplier selection in interval type-two fuzzy environment. An extended novel TODIM method based on prospect theory to solve multiple criteria group decision making problem under interval type-2 fuzzy sets environment was developed. A green supplier selection example was provided to demonstrate the usefulness of the proposed method. P.J. Ren [3] presented a Pythagorean fuzzy TODIM approach to multi-criteria decision making. D.C. Liang [4] gave a new extension of TOPSIS method for multiple criteria decision making with hesitant Pythagorean fuzzy sets, and conducted simulation tests to analyse how the risk attitudes of the decision makers exert the influence on the results of MCDM under uncertainty. At last, a case study was made to show the applicability of the proposed approach. J. Hong [5] established a cost benefit analysis framework to explore the basic cost composition of prefabrication and examined the effect of adopting prefabrication on the total cost of real building projects. He made a point that future focus should lie in providing financial support for promoting the development of prefabrication technology, optimizing the structure integrity of prefabricated buildings, and improving the maturity of the precast market. X. Wang [6] proposed a multiple attribute decision-making method with the interval grey number based on the improved TODIM method. By analysing the insufficient of the dominance degree and the overall value in the classic TODIM method, the representation of the new dominance degree and overall dominance degree of the gain or loss of one alternative relative to other alternatives was given. An example was also presented to illustrate the usefulness and effectiveness of the proposed method.

*Corresponding author: ${ }^{\mathrm{a}}$ yy20052710@163.com 
This paper makes a special effort to investigate and study on the evaluation and prediction model of prefabricated plant site by BP neural network, and the model proposed in this paper can provide effective support in the selection of prefabricated plant site.

\section{Theory of BP neural network}

Assuming that the BP network has a total of L layers, and the expected output of network for given $P$ samples can be expressed in formula (1).

$$
\mathrm{T}_{\mathrm{d}}=\left[\mathrm{T}_{\mathrm{d} 1}, \mathrm{~T}_{\mathrm{d} 2}, \ldots \ldots, \mathrm{T}_{\mathrm{dp}}\right]
$$

When the $P$ sample is input, the operating characteristics of the $j$ neuron in the $i(i=1,2, \ldots \ldots, L-1)$ layer in the network are expressed in formula (2) and (3).

$$
\begin{gathered}
n e t_{j p}^{(l)}=\sum_{i=1}^{n_{l-1}} W_{j i}^{(l)} O_{i p}^{(l-1)}-\theta_{j}^{l} \\
O_{j p}^{(l)}=f_{l}\left(\text { net }_{j p}^{(l)}\right)
\end{gathered}
$$

Where $W_{i j}$ is the connection weight of the neuron $i$ to the neuron $j, n_{l-1}$ is number of nodes in layer $i-1, O_{j p}^{(l-1)}$ is current input of neuron $j, O_{j p}^{(l)}$ is the output of neuron $j$, and $f_{l}$ is nonlinear and differential non-decreasing function, generally taken as the S-function, namely expressed in formula (4).

$$
f_{l}(x)=\frac{1}{1+e^{-x}}
$$

For the output layer, the output of neuron $j$ uses the following expression in formula (5).

$$
O_{j p}^{(L)}=f_{L}\left(n e t_{j p}^{(L)}\right)=\sum_{i=1}^{n_{L-1}} W_{j i}^{(L)} O_{i p}^{(L-1)}-\theta_{j}^{L}
$$

The purpose of neural network learning is to minimize the output error of each sample, and the error of every sample can be expressed in formula (6).

$$
E_{p}=\frac{1}{2} \sum_{j=1}^{m}\left(T_{j d p}-\hat{T}_{j p}\right)^{2}(\mathrm{p}=1,2, \ldots \ldots, \mathrm{p})
$$

Where $T_{j d p}$ is the expected output of the $j$ node in the output layer, $\widehat{T}_{j p}$ is the actual output of the $j$ node in the output layer, and $m$ is the number of output nodes.

The output error of each sample is the minimum to ensure that the total network error reaches the minimum. The total error can be expressed in formula (7).

$$
E=\sum_{p=1}^{P} E_{p}
$$

Gradient algorithm is adopted to modify the network weights and thresholds. The iterative equation of the weight coefficient in layer $i$ is expressed in formula (8).

$$
\begin{gathered}
W(k+1)=W(k)+\Delta_{p} W(k+1) \\
W=\left\{w_{i j}\right\}
\end{gathered}
$$

Where $k$ indicates the iteration number.

Let the formula (9) and formula (10) equations be established, and the formula (11) can be obtained.

$$
\begin{gathered}
\Delta_{p} w_{j i} \infty-\frac{\partial E_{p}}{\partial w_{i j}^{(l)}}-\frac{\partial E_{p}}{\partial w_{i j}^{(l)}}=-\frac{\partial E_{p}}{\partial n e t_{j p}^{(l)}} \frac{\partial n e t_{j p}^{(l)}}{\partial w_{i j}^{(l)}} \\
=-\frac{\partial E_{p}}{\partial n e t_{j p}^{(l)}} O_{i p}^{(l-1)} \\
\delta_{p j}^{(l)}=-\frac{\partial E_{p}}{\partial n e t_{j p}^{(l)}} \\
\Delta_{p} w_{j i}=\eta \delta_{p j}^{(l)} O_{i p}^{(l-1)}
\end{gathered}
$$

Where $\eta$ means step-size. And the principle of BP neural network can be described in the Figure 1.

\begin{tabular}{|c|c|c|c|}
\hline Standards & Description & $\begin{array}{l}\text { Assignment } \\
\text { weight }\end{array}$ & $\begin{array}{c}\text { Standard } \\
\text { weight }\end{array}$ \\
\hline $\mathrm{C}_{1}$ & Location & 5 & 0.20 \\
\hline $\mathrm{C}_{2}$ & Topography & 3 & 0.12 \\
\hline $\mathrm{C}_{3}$ & Land scale & 3 & 0.12 \\
\hline $\mathrm{C}_{4}$ & $\begin{array}{l}\text { Transportation } \\
\text { facilities }\end{array}$ & 3 & 0.12 \\
\hline $\mathrm{C}_{5}$ & $\begin{array}{l}\text { Availability of raw } \\
\text { materials and labor }\end{array}$ & 2 & 0.08 \\
\hline $\mathrm{C}_{6}$ & Project cost & 4 & 0.16 \\
\hline $\mathrm{C}_{7}$ & $\begin{array}{l}\text { Availability of } \\
\text { water, electricity and } \\
\text { drainage systems }\end{array}$ & 3 & 0.12 \\
\hline $\mathrm{C}_{8}$ & $\begin{array}{l}\text { Policy and } \\
\text { regulatory risks }\end{array}$ & 1 & 0.04 \\
\hline $\mathrm{C}_{9}$ & $\begin{array}{l}\text { Incidence of } \\
\text { natural } \\
\text { disasters }\end{array}$ & 1 & 0.04 \\
\hline
\end{tabular}

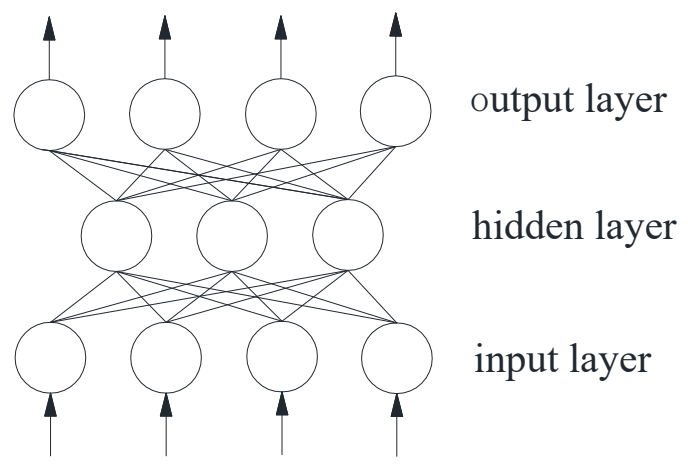

Figure 1. Principle of BP neural network

\section{Model development and application}

The study was based on the site selection data in reference [1]. Table 1 is the standard list drawn according to their importance and weight in the site selection process. Numbers reflect the relative importance of each factor. Weight was formulated by decision makers and was normalized to make the result more accurate. The qualitative and quantitative criteria were comprehensively considered in this study.

Table 1. Ranking of standard weight and normalized weight 
The parameters entered in the model are $\mathrm{C} 1 \sim \mathrm{C} 9$ in Table 1, while the sample data in the site selection are shown in Table 2.

Table 2. Scheme evaluation

\begin{tabular}{|c|c|c|c|c|c|c|c|c|c|}
\hline & $\mathrm{C}_{1}$ & $\mathrm{C}_{2}$ & $\mathrm{C}_{3}$ & $\mathrm{C}_{4}$ & $\mathrm{C}_{5}$ & $\mathrm{C}_{6}$ & $\mathrm{C}_{7}$ & $\mathrm{C}_{8}$ & $\mathrm{C}_{9}$ \\
\hline $\mathrm{A}_{1}$ & 2 & 3 & 1200 & 2 & 1 & 1 & 2 & 2 & 0 \\
\hline $\mathrm{A}_{2}$ & 3 & 4 & 800 & 0 & 1 & 1 & 2 & 2 & 2 \\
\hline $\mathrm{A}_{3}$ & 2 & 2 & 870 & 2 & 3 & 3 & 3 & 1 & 1 \\
\hline $\mathrm{A}_{4}$ & 4 & 3 & 500 & 3 & 1 & 1 & 2 & 2 & 0 \\
\hline $\mathrm{A}_{5}$ & 2 & 1 & 1000 & 3 & 1 & 1 & 3 & 1 & 0 \\
\hline $\mathrm{A}_{6}$ & 3 & 4 & 950 & 2 & 1 & 1 & 1 & 0 & 2 \\
\hline $\mathrm{A}_{7}$ & 1 & 2 & 450 & 1 & 2 & 2 & 0 & 0 & 2 \\
\hline $\mathrm{A}_{8}$ & 2 & 4 & 990 & 3 & 1 & 1 & 3 & 2 & 1 \\
\hline $\mathrm{A}_{9}$ & 4 & 4 & 380 & 2 & 1 & 1 & 3 & 1 & 1 \\
\hline $\mathrm{A}_{10}$ & 1 & 4 & 1170 & 0 & 1 & 1 & 0 & 0 & 2 \\
\hline $\mathrm{A}_{11}$ & 3 & 2 & 1090 & 2 & 2 & 2 & 2 & 2 & 1 \\
\hline $\mathrm{A}_{12}$ & 4 & 4 & 730 & 2 & 0 & 0 & 2 & 2 & 2 \\
\hline
\end{tabular}

The TODIM approach can characterize the decision makers' psychological behaviours under risk, and it has been introduced to handle multi-criteria decision making problems. The application of mathematical formula of TODIM brought the normalized scheme score matrix and normalized global value, which are shown in Table 3.

Table 3. Final value and arranging order

\begin{tabular}{|c|c|}
\hline Scheme & Normalized global value \\
\hline $\mathrm{A}_{1}$ & 0.63656 \\
\hline $\mathrm{A}_{2}$ & 0.58604 \\
\hline $\mathrm{A}_{3}$ & 0.54206 \\
\hline $\mathrm{A}_{4}$ & 0.63384 \\
\hline $\mathrm{A}_{5}$ & 0.27884 \\
\hline $\mathrm{A}_{6}$ & 0.47847 \\
\hline $\mathrm{A}_{7}$ & 0 \\
\hline $\mathrm{A}_{8}$ & 1 \\
\hline $\mathrm{A}_{9}$ & 0.69482 \\
\hline $\mathrm{A}_{10}$ & 0.017472 \\
\hline $\mathrm{A}_{11}$ & 0.87203 \\
\hline $\mathrm{A}_{12}$ & 0.92055 \\
\hline & \\
\hline
\end{tabular}

The BP neural network model was built by taking prefabricated factory sites, topography, land scale, transportation facilities, availability of raw materials and labor, project cost, availability of water, electricity and drainage systems, policy and regulatory risks, the incidence of natural disasters as input layer elements, regarding normalized global value as output layer element, and adopting Tansig function as the transfer function of neural in hidden layer, Traingdm function as the training function, and Logsig function as the transfer function of neural in output layer. Moreover, frequency of training was designed to be 2000 , the training target was required to reach 0.01 , and the learning rate was formulated as 0.06 . If the allocation of parts of either memory or disk space had been exhausted before a calculation process was complete, an error message that memory or disk space would run out. Its calculation process and training state were shown in Figure 2 and Figure 3. Accuracy verification of model prediction was shown in Figure 4.

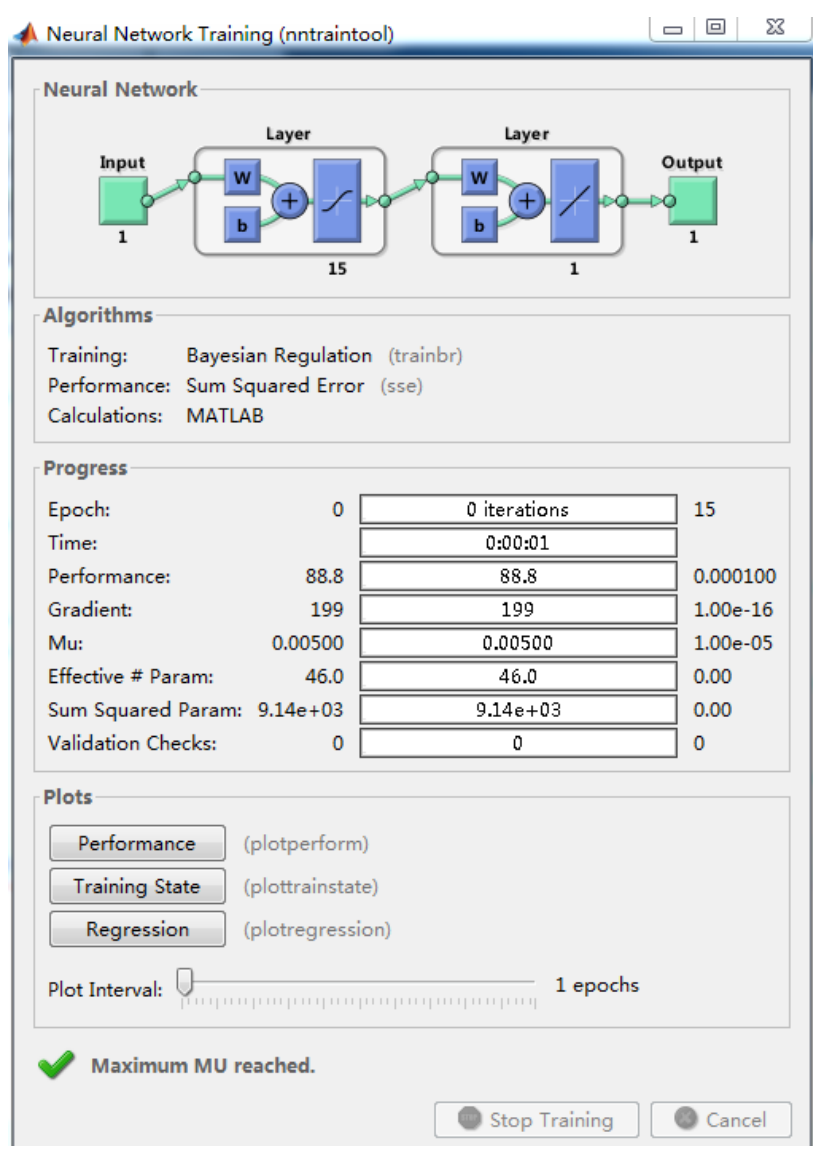

Figure 2. BP model calculation

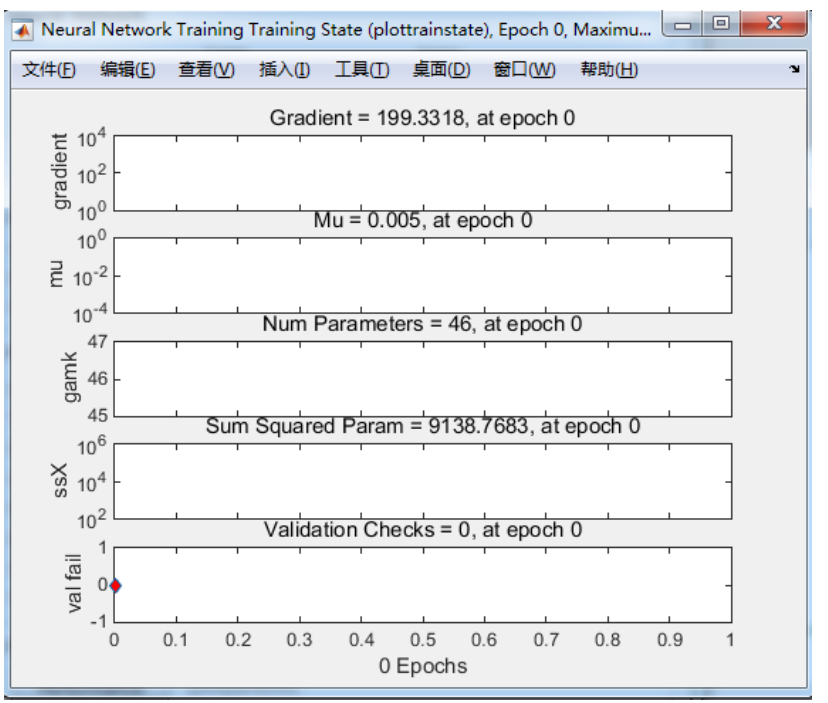

Figure 3. Training state of model 


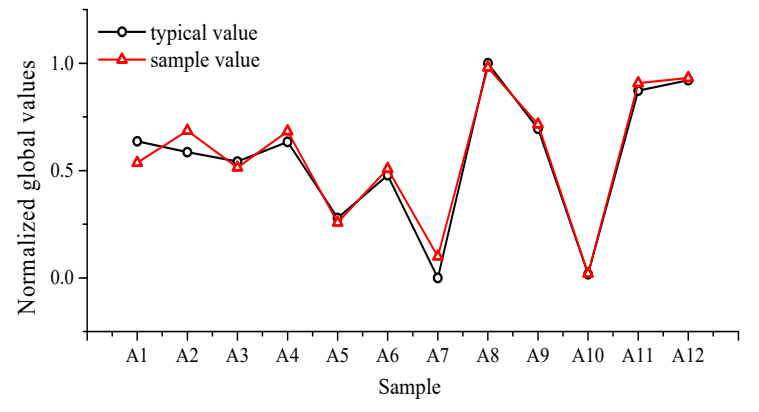

Figure 4. Accuracy verification of model prediction

As shown in Figure 4, the model prediction result had a good accuracy, which was not much different from the expected value. If the input sample size can be increased, the prediction accuracy of the model will be better. When selecting the sites of prefabricated plant, the first step is to ensure some related factors including the plant site, topography, land scale, transport facilities, availability of raw materials and labour, project cost, availability of water, electricity and drainage systems, policy and regulatory risks, incidence of natural disasters, the second step is to input data to corresponding input layer respectively according to the scoring system. Finally, the normalized global value will be calculated, which can judge the quality of site selection. If the input data is the score of the current prefabricated plants in Chengdu and Chongqing areas, the normalized global value of the prefabricated plant that meet conditions in Chengdu and Chongqing will be obtained.

\section{Conclusion}

This evaluation method took prefabricated plant sites, topography, land scale, transportation facilities, availability of raw materials and labour, project cost, availability of water, electricity and drainage systems, policy and regulatory risks, incidence of natural disasters into account. Moreover, establishing the site model of prefabricated plant by BP neural network, which analysed the various possibilities of site selection. Finally, normalized global values was calculated, which evaluated the pros and cons of location. It is beneficial for decision makers to achieve the better alternative. From the results of this study, the method can provide effective support for the site selection of prefabricated plant.

\section{Acknowledgements}

This work was supported by National 13th Five-year Key Research and Development Program of China (2016YFC0701909-1), Fundamental Research Funds for the Central Universities (106112017CDJXY200009, 106112016CDJRC000101).

\section{References}

1. S.H. Jiang, M.A. Terefe, N. Wang, Study on selecting of prefabricated plant site basing on TOMID, project management. 233, 7 (2016) 14-21.

2. J.D. Qin, X.W. Liu, W. Pedrycz, An extended TODIM multi-criteria group decision making method for green supplier selection in interval type2 fuzzy environment, Eur. J. Oper. Res, 258 (2017) 626-638

3. P.J. Ren, Z.S. Xu, X.J. Gou, Pythagorean fuzzy TODIM approach to multi-criteria decision making, Appl. Soft. Comput, 42 (2016) 246-259.

4. D.C. Liang, Z.S. Xu, The new extension of TOPSIS method for multiple criteria decision making with hesitant Pythagorean fuzzy sets, Appl. Soft. Comput, 60 (2017) 167-179.

5. J. Hong, Q.P. Shen, Z.D. Li, B.Y. Zhang, W.Q. Zhang, Barriers to promoting prefabricated construction in China: A cost-benefit analysis, J. Clean. Prod, 172 (2018) 649-660.

6. X. Wang, Y.G. Dang, Multiple attribute decisionmaking model with interval grey number based on improved TODIM method, Contr. And Decision., 31(2016) 261-266. 